\title{
Investigation on Body Shaping Garments Using 3D- Body Scanning Technology and 3D-Simulation Tools
}

\author{
Michael ERNST*, Ute DETERING-KOLL*, Dorothee GÜNTZEL* \\ Niederrhein University of Applied Sciences, Mönchengladbach, Germany
}

\begin{abstract}
This paper presents a practical approach on the way to investigate the real benefit of shaping structures within a digital product development process in the apparel industry and within an ongoing quality control and points out the status quo of these products in the market.

Investigations have been carried out using different body shaping garments (so called panties and shirts/tops) within a sample size of 6 different female bodies- covering the ageing structure from 20 to 60 years old.

The reducing and the deceiving effect were measured using 3D body scanning technology (ScanworX 2.9.12; Anthroscan; Human Solutions $\mathrm{GmbH}$ ) and extracting and overlapping circumference measurements and body shaping structures in cutting planes. [3]

In additional scanatars have been developed from the test persons with and without shaping structures and tested against close fitting women's outer garments to show the effect in a wearing situation by using 3D simulation software tools. [1, 2]
\end{abstract}

Keywords: Body shaping garments, compression textiles, 3d body scanning, scanatar, 3D simulation, product development

\section{Introduction}

Nowadays compression textiles are used in various applications: From medical textiles over power enhancing sports textiles to body shaping garments in lingerie industry.

Especially body shaping structures for the last application are gaining more and more attention due to a changing society, an increasing importance of comparing and rating individual body shapes and a growing demand on esthetic expression- especially for female attraction.

Products in the market are promising a visible reduction of body dimension in the area of belly, tummy, bottom, thigh, hip or accentuating bust or bottom area. [4]
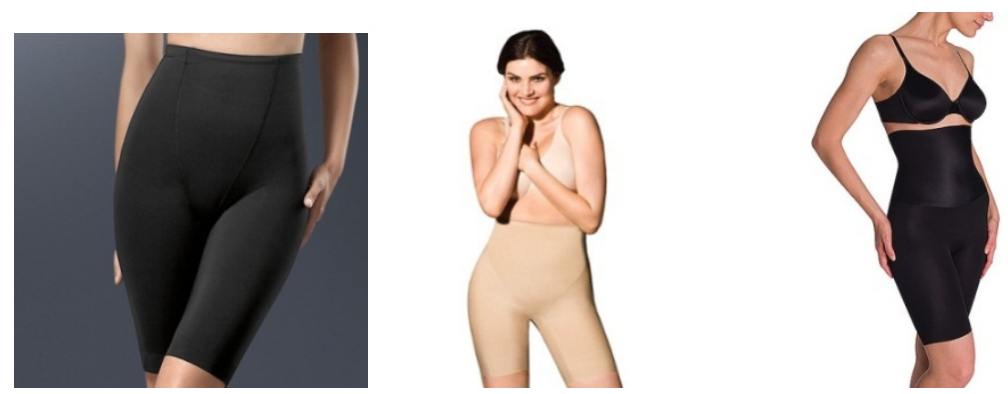

Fig.1.1. Body shaping structures - Huber, Anette Diva, Naomi\&Nicole.

Within this topic questions arise concerning the real effect of such structures with regard to the size problems by choosing the right size on one side and comfort properties on the other side.

At least several possibilities to achieve this effect are given by the fact of different price levels and quality standards for different target groups- e.g. using so called power nets to stabilize the shape, using special yarn constructions and special pattern constructions.

Within the product development process of these garments it is compulsory necessary to know the real effect on different bodies within different ageing groups to enhance the benefit for the customers and to keep up with a steady growing market. 


\section{Market}

Products in the product range of underwear shaping garments in the market are mainly based on polyamide/nylon, polyester and elastane/spandex, sometimes within a mix/blend of nature cotton and mainly divided up to so called cut and sewn products or finished circular knitted products. Cut and sewn products are offered on a lower price level due to the manufacturing technology with cutting pattern panels and joining them by applying sewing or more innovative- bonding technics. So called power nets or meshes are used for an improved stabilization and compression of selected body parts within higher "genre" products. [5]

Unfortunately the real compression effect is difficult to measure because of a limited advisory service offered to the target group and finally to the customer. The problem of acceptance and compliance arises especially with regard to thermophysiological comfort properties (heat flow and water vapour transmission) and skin sensorial comfort properties and therefore the balance between shaping on one side and comfort loss on the other side has to be equalized within the product development process.

\section{Research methodology}

In this paper only a small part of the project results is presented: the complete one includes investigations on body shaping underwear garments including investigations on shaping bras and body shaping garments of the second layer. Questionnaires to monitor the real wearing situation over a period of several weeks under different environment conditions are also part of the research.

In this paper the focus is on shaping underwear structures and few selected results are presented in chapter 4.

\subsection{Sample group}

Within this project six females have been selected representing different ageing groups and different weight groups to cover a broad range of influence parameters given by the target group itself.

All six females have signed an agreement that the results- measurements, scans and photos can be used for research and can be published and presented.

Table 3.1. Overview of sampling group female.

\begin{tabular}{|l|l|l|l|l|l|l|}
\hline No & age & weight & BMI & height & additional information & size \\
\hline$F_{1}$ & 28 & 59 & 20,5 & 169,7 & & 38 \\
\hline$F_{2}$ & 26 & 95 & 29,8 & 178,5 & & 48 \\
\hline$F_{3}$ & 48 & 89 & 29,8 & 172,9 & abdominal reduction surgery & 46 \\
\hline$F_{4}$ & 61 & 75 & 23,2 & 179,8 & & 42 \\
\hline$F_{5}$ & 55 & 73 & 26,1 & 167,2 & & 42 \\
\hline$F_{6}$ & 62 & 84 & 28,1 & 172,9 & & 44 \\
\hline
\end{tabular}

BMI (body mass index) $=$ weight $/$ height $^{2}$

\subsection{Products}

To be award of the status quo concerning shaping structures on the market a pre study was undertaken to get this information. According to the basics given in chapter 2 different structures have been selected- different in fabric and composition, manufacturing methods and garment: top, body, panty short and panty long. In a second step of this project the underwear shaping structures are replaced by second layer shaping structures and investigated especially for the career success of women in business sector.

An overview of the investigated shaping structures in part one of this project, is given in table 3.2:

Table 3.2. Overview of investigated shaping structures.

\begin{tabular}{|c|c|c|c|c|c|c|}
\hline Supplier & $\mathrm{S}_{1}$ & $\mathrm{~S}_{2}$ & $\mathrm{~S}_{3}$ & $\mathrm{~S}_{4}$ & $\mathrm{~S}_{5}$ & $\mathrm{~S}_{6}$ \\
\hline Panty short & & $\begin{array}{l}92 \% \text { PA } \\
8 \% \text { EL }\end{array}$ & & $\begin{array}{l}90 \% \text { PA } \\
10 \% \text { EL }\end{array}$ & & \\
\hline Panty long & $\begin{array}{l}85 \% \text { PA } \\
15 \% \text { El }\end{array}$ & $\begin{array}{l}92 \% \text { PA } \\
8 \% \text { EL }\end{array}$ & & $\begin{array}{l}90 \% \text { PA } \\
10 \% \text { EL }\end{array}$ & $\begin{array}{l}76 \% \text { PA } \\
24 \% \text { EL }\end{array}$ & $\begin{array}{l}80 \% \text { PA } \\
18 \% \text { El } \\
2 \% \mathrm{CO} \\
\end{array}$ \\
\hline Top & $\begin{array}{l}85 \% \text { PA } \\
15 \% \text { EL }\end{array}$ & & & $\begin{array}{l}90 \% \text { PA } \\
10 \% \text { EL }\end{array}$ & $\begin{array}{l}76 \% \text { PA } \\
24 \% \text { SP } \\
\end{array}$ & \\
\hline Body & & & $\begin{array}{l}82 \% \text { PET } \\
18 \% \text { EL }\end{array}$ & & & $\begin{array}{l}80 \% \mathrm{PA} \\
18 \% \mathrm{El} \\
2 \% \mathrm{CO}\end{array}$ \\
\hline
\end{tabular}


In figure 3.1 three of the products: top, panty short and panty long are shown. Especially the shaping effect implemented by panel and seam structures (cover and flat lock seams) is visible. Usually the garments are available in three colors: white, champagne and black. The size for each candidate of the sampling group was chosen according to their body measurements and the size table available from each supplier. In few cases two sizes have been investigated to check the sizes and to investigate the increasing effect due to smaller size selection.

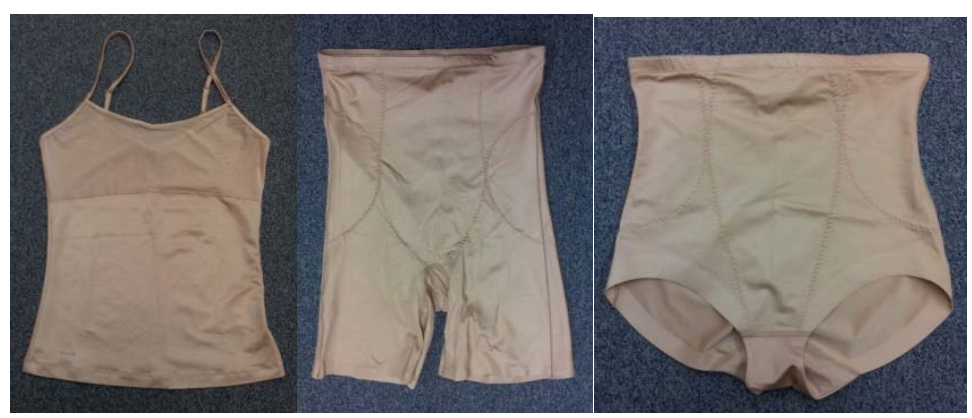

Fig.3.1. Example of top $\left(S_{1}\right)$, panty long $\left(S_{2}\right)$ and panty short $\left(S_{2}\right)$, color champagne cut \& sewn.

In figure 3.2 the shaping underwear is shown in a wearing situation of female $F_{6}$ with product panty short $S_{2}$ and panty long $S_{1}$.It is visible that the short panty of supplier $S_{2}$ (figure 3.2 a)) leads to compression but also to a visible movement of the flabby tissue on the top waist end and therefore more to a distortion. Otherwise the product panty long of supplier $S_{1}$ runs up to the under-bust line and compresses also the upper part not covered by the short panty.

a)

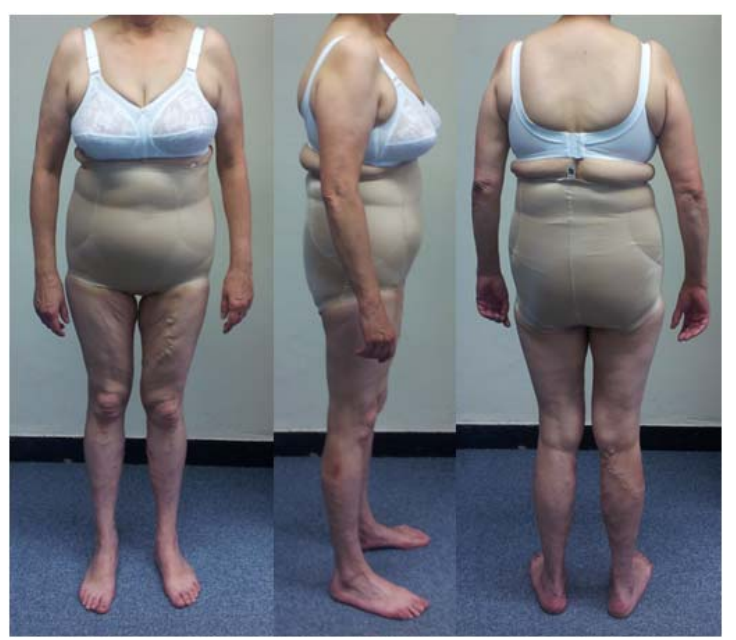

b)

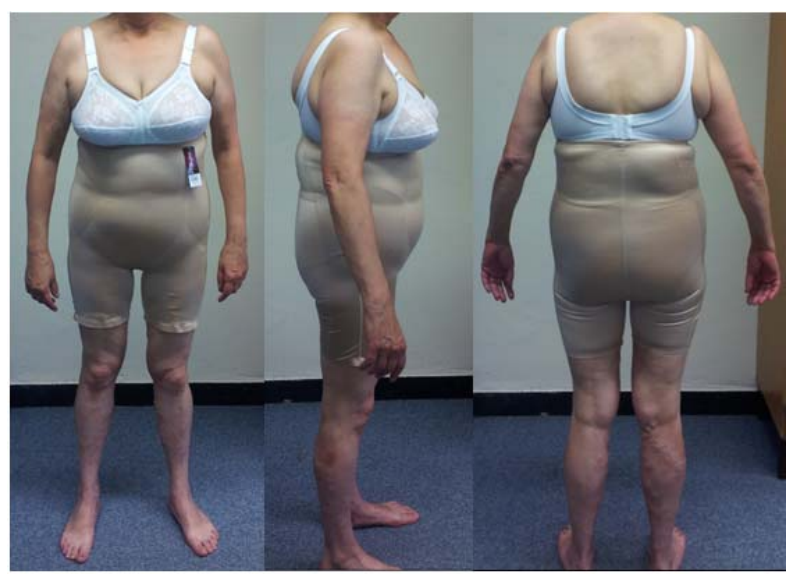

Fig. 3.2. Example of female $\left(F_{6}\right)$ age 62

a) front, side view, back with shaping structure panty short $S_{2}$ b) front, side view, back with shaping structure panty long $S_{1}$. 


\subsection{Body scanning technology}

Investigation on body shaping structures using manually taken measurements was detected as not suitable for achieving accurate and statistically acceptable results. [3] Therefore the grid technology by drawing a detailed grid on a tight fitting outer garment and taken measurements and landmarks was replaced by using a 3D body scanner for taking detailed body measurements (Anthroscan Human Solutions). [5]

Although running all investigations with the 3D body scanner the main measurements for bust, under bust, waist and hip were always taken for each candidate and each underwear system manually to control the process and if necessary to adjust the extracted scan measurement position for improving the comparison of test results.

Within this project three scan positions have been chosen:

- Scan position (classic)

- Relaxed position

- Sitting position

The classic and the relaxed position are also both used to generate the scanatar for the 3D simulation. The following figure shows the three scan positions taken with female $F_{3}$ wearing a combination of $S_{1}$ top and $\mathrm{S}_{1}$ panty long.

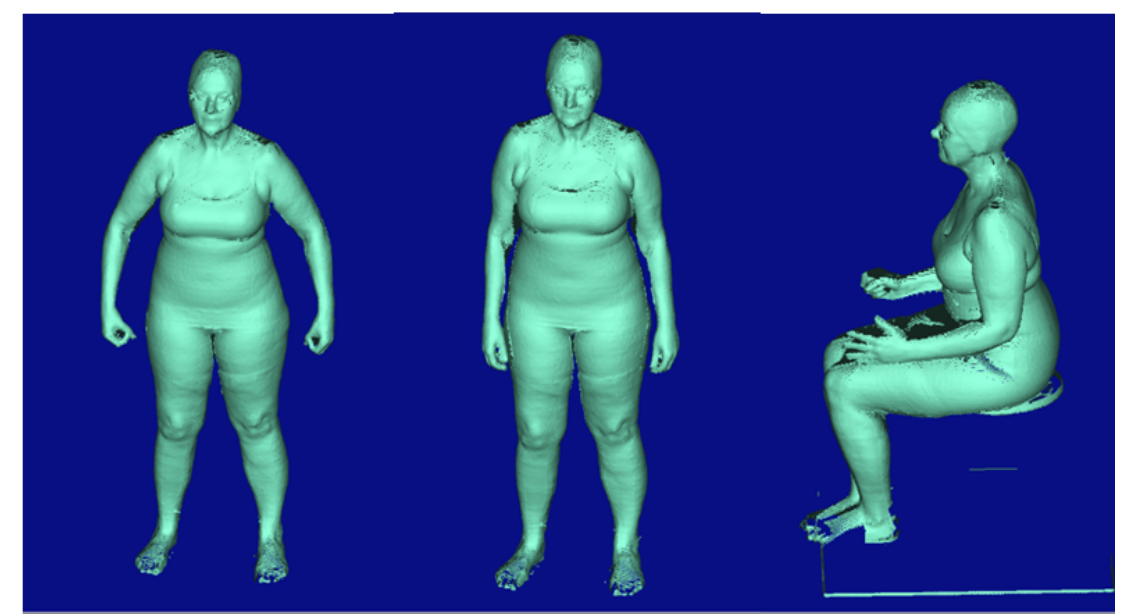

Fig. 3.3. Scanning in three positions $F_{3}$; scan, relaxed and sitting; with Human Solutions, Anthroscan.

All 6 females have been scanned with common underwear, with shaping structures according to table 3.2, with common underwear + tight fitting clothing and with shaping underwear + tight fitting clothing. Additionally photos have been taken from front back and side view to control and correlate the resultsespecially for the dimensions by investigating plane sections of different axes.

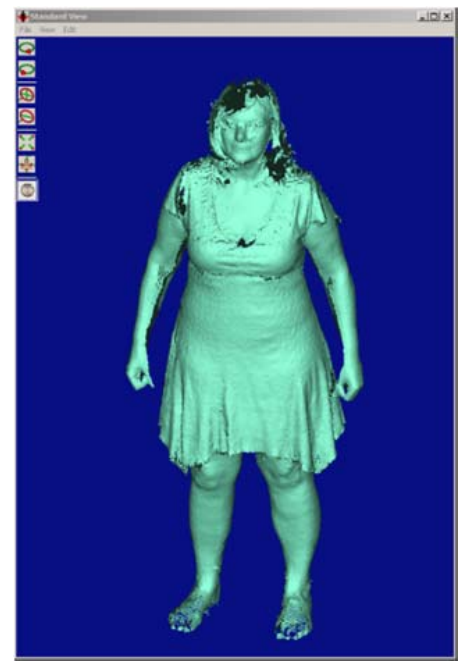

Fig. 3.4. Example of scan with shaping underwear + tight fitting clothing; $F_{3} S_{1} l o n g$. 


\subsection{Scanatar}

Using the Humans Solutions Anthroscan Scanner and scanning software enables to generate so called scanatars using a special wizard guiding through the process.[3] The scanatar is an avatar from an individual person and represents the virtual mannequin of a real person with identical body measurements and shapes. Two scan positions (scan and relaxed position) are necessary- already included in the scanning test procedure in this project. [2]

In figure 3.5 a step of the wizard procedure for generating scanatars $\left(F_{3}\right)$ is shown.

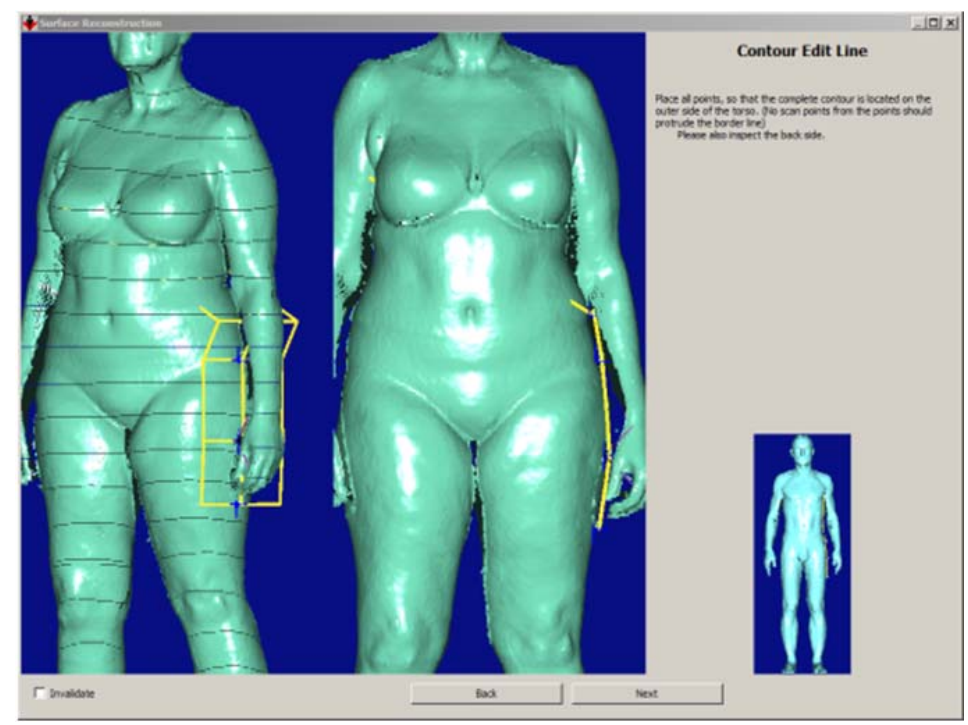

Fig. 3.5. Wizard procedure for generating scantars; example $F_{3}$ without shaping structure.

\subsection{D simulation and fit/body-distance control}

The generated scanatar files obj. were exported and imported to different 3D CAD systems available at Niederrhein University:

- vidya assyst

- CLO3D, 3D

- Prototyping Lectra

- Design Concept

- OptiTex 3D runway

- V-stitcher Browzwear

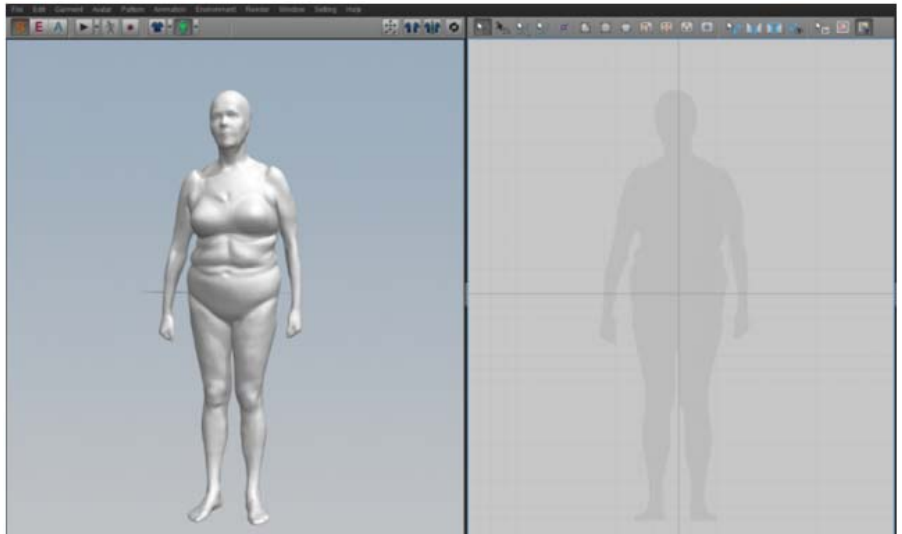

Fig. 3.6. Scanatar $\left(F_{6}\right)$ imported to CLO3D.

All systems offer 3D fitting tests with virtual sewn garments and material characteristics. Different investigation tools are implemented by detecting body distance control, pressure and tension mapping, elasticity in warp, weft and bias direction. Design Concept and OptiTex also offer the possibility of flattening down from 3D to 2D- the last one with complete interactivity between $2 \mathrm{D}$ and $3 \mathrm{D}$. $[1,6,7,8$, 9] Within this project the main interest was in investigating virtual fitting tests with tight fitted garments on scanatars with and without shaping underwear. 


\subsection{Research methodology}

In figure 3.7 an overview of the complete research methodology for part 1 of the shaping project is given. Starting with a target investigation group of six female persons (age 26- 62) and scanning in different scanning positions with different underwear systems and in addition with tight fitting clothing systems as outer layer the measurements have been extracted by using Anthroscan Human Solutions software. In a second step plane sections of the three axes have been exported to a vector graphic program to achieve an overlay of the sections referring to different underwear structures to finally highlight the shaping effects in detail. In a third step the generated scanatars have been used to verify the results by using different 3D CAD systems and by carrying out virtual fitting tests with tight fitting clothing.

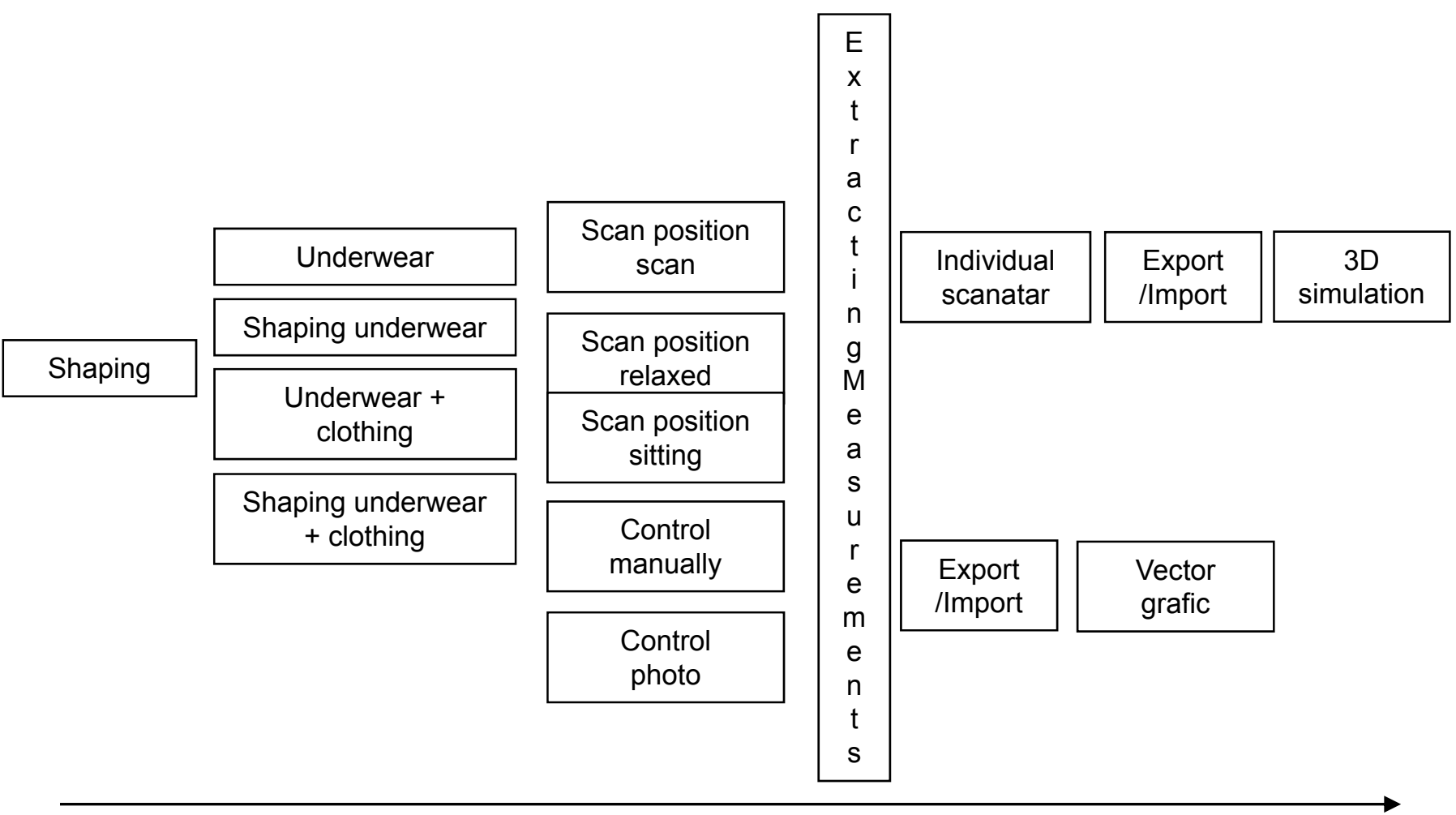

Fig. 3.7. Overview of research methodology part 1 for investigating shaping structures.

\section{Results}

In this chapter some results are highlighted to show the effect of the investigated shaping structures concerning the

- Shaping effect

- Compression effect

- Smoothing effect

- Virtual Fitting

on body structures.

Results of age and body shape/structure influence also obtained will be only part of the presentation due to details and privacy of the investigated group of females.

\subsection{Shaping effect}

An overlay of plane sections in $x$-axis with different height from ground as reference has been achieved by exporting the results to a vector based program (Kaledo style Lectra). Within this program two or more plane sections can be over-layered and illustrated for a detail view on the effect in different axes. 
The horizontal cut in defined height of $104 \mathrm{~cm}$ from ground (waist area) for female $F_{3}$ is shown in figure 4.1a). Especially for the front part the shaping effect is detectable with a reduction of circumference from $104.5 \mathrm{~cm}$ to $102.6 \mathrm{~cm}$ in total by wearing the long panty of supplier $\mathrm{S}_{4}$. The shaping effect for the front side was also detected by an overlay of plane section in z-axis- body center over the length of the compression panty long shown in figure $4.1 \mathrm{~b}$ ).

The two pictures presented below are representative for the procedure of exporting the plane sections with chosen reference of basic ground and respect to the scale size given for each section in the evaluation program. The "negative" shaping effect in center back of the plane section in figure 4.1 a) is due to a typical strong elastic behavior of the investigated garment and smoothing effect of concave body parts.

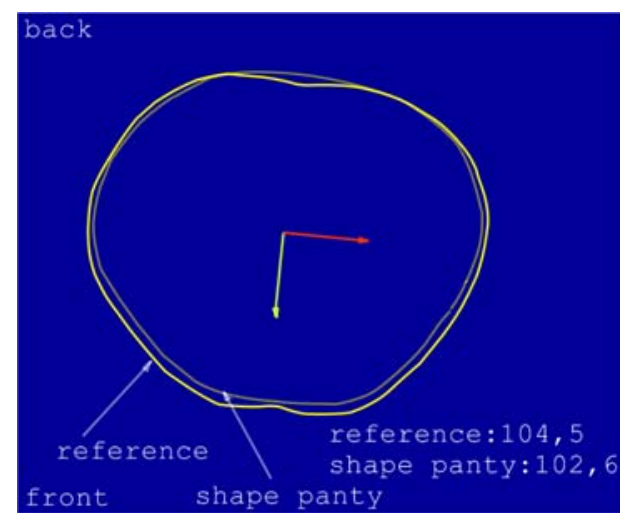

a)

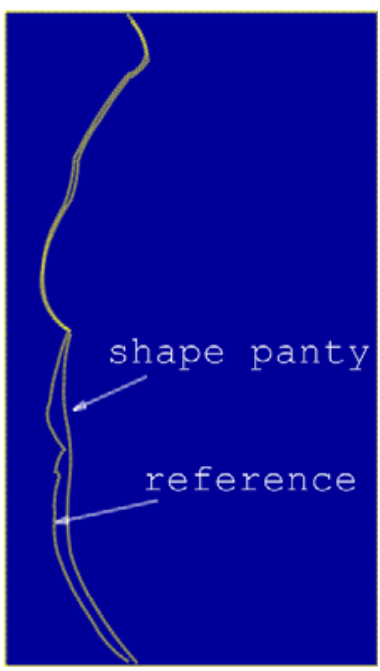

Fig. 4.1. a) Overlay of plane section waist area $x$-axis $F_{3} ; 104 \mathrm{~cm}$ from ground; scan with and without compression panty long $\mathrm{S}_{4}$

b) Overlay of plane section z-axis $F_{3}$; scan with and without compression panty long $S_{4}$

\subsection{Compression effect}

In figure 4.2 different scans with and without shaping structures are shown for female $F_{6}$. The compression effect of the garments is visible also the missing fit of the leg ends of the garment typically for $F_{6}$ with an age of 62 years.

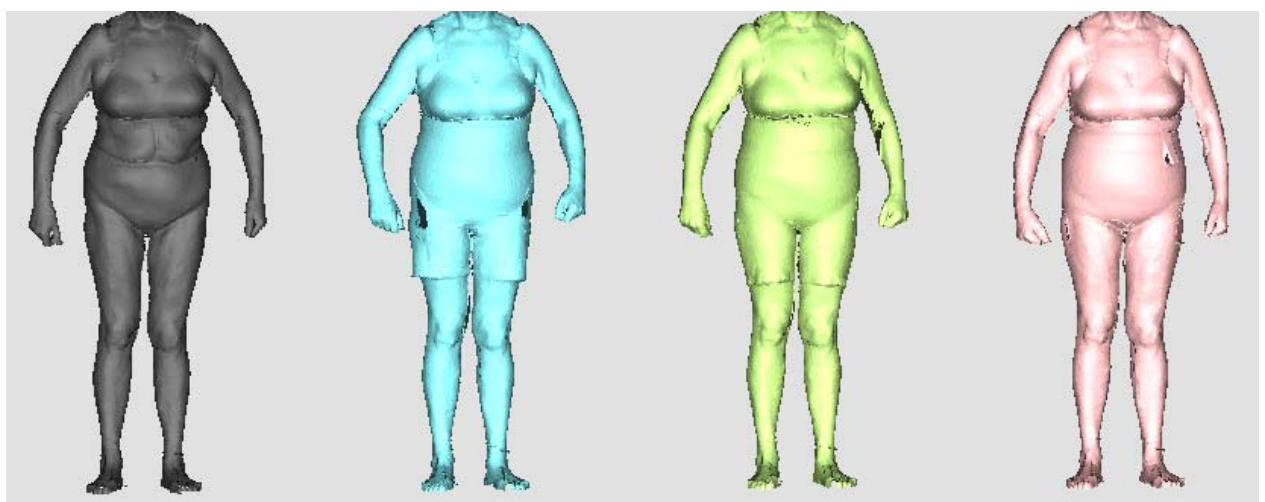

Fig. 4.2. Overview scans candidate $F_{6}$ without and with $S_{1}$ panty long, $S_{2}$ panty long and $S_{2}$ panty short.

A more detailed view with comparing measurements is given in table 4.1.

Product $S_{1}$ panty long shapes between $85 \mathrm{~cm}$ and $110 \mathrm{~cm}$ from ground with a maximum of $3.3 \mathrm{~cm}$ at $110 \mathrm{~cm}$ position.

Product $\mathrm{S}_{2}$ panty long shapes between $95 \mathrm{~cm}$ and $115 \mathrm{~cm}$ (upper end position) with a maximum of 2.3 $\mathrm{cm}$ at $100 \mathrm{~cm}$ position and product $S_{2}$ panty short shapes between $80 \mathrm{~cm}$ and $110 \mathrm{~cm}$ with a maximum of $2.8 \mathrm{~cm}$ at the upper end and therefore at a really bad position which causes an upward moving of flappy tissue already shown in figure $3.2 a$ ). 
Table 4.1. Measurements circumferences F6 referring to height level from ground.

\begin{tabular}{|l|l|l|l|l|}
\hline \begin{tabular}{c} 
Coordinate $\begin{array}{c}\text { z } \\
\text { [cm] } \\
\text { from ground }\end{array}$ \\
\cline { 2 - 5 }
\end{tabular} & $\begin{array}{l}\text { Orig } \\
\text { Right/left }\end{array}$ & $\begin{array}{l}\mathrm{S}_{1} \text { panty long } \\
\text { Right/left }\end{array}$ & $\begin{array}{l}\mathrm{S}_{2} \text { panty long } \\
\text { Right/left }\end{array}$ & $\mathrm{S}_{2}$ panty short \\
\hline 65 & $50,3 / 48,3$ & $50,9 / 48,1$ & $49,9 / 48,2$ & \\
\hline 70 & $54,7 / 54,8$ & $55,2 / 54,5$ & $55 / 55,1$ & \\
\hline 75 & 91,4 & 92,7 & 88,4 & \\
\hline 80 & 96,7 & 97 & 97,1 & 95 \\
\hline 85 & 100,7 & 99,5 & 101,0 & 98 \\
\hline 90 & 106,5 & 105,1 & 107,3 & 104,4 \\
\hline 95 & 109,8 & 108,1 & 109,6 & 108,1 \\
\hline 100 & 105,8 & 105,7 & 103,4 & 106,2 \\
\hline 105 & 102 & 99,8 & 100,0 & 102,1 \\
\hline 110 & 100,3 & 97 & 100 & 97,2 \\
\hline 115 & 98,3 & 100,7 & 99,6 & \\
\hline
\end{tabular}

The results shown in figure 4.1 are detected the same for the other candidates, with different measurements in coordinate $\mathrm{z}$ from ground due to different tissue conditions (soft, flabby, tight) respectively caused by different age. The compression effect is not distributed as known from medical compression textiles with an implemented gradient and more related to smoothing effects over the length of the shaped body part. Thus also negative effects have to be considered depending on the maximum value of compression achieved.

\subsection{Smoothing effect}

In figure 4.3 different scans with and without shaping structures are shown for female $F_{1}$.

The smoothing effect of the different garments is visible by regarding the silhouette of the body in detail.
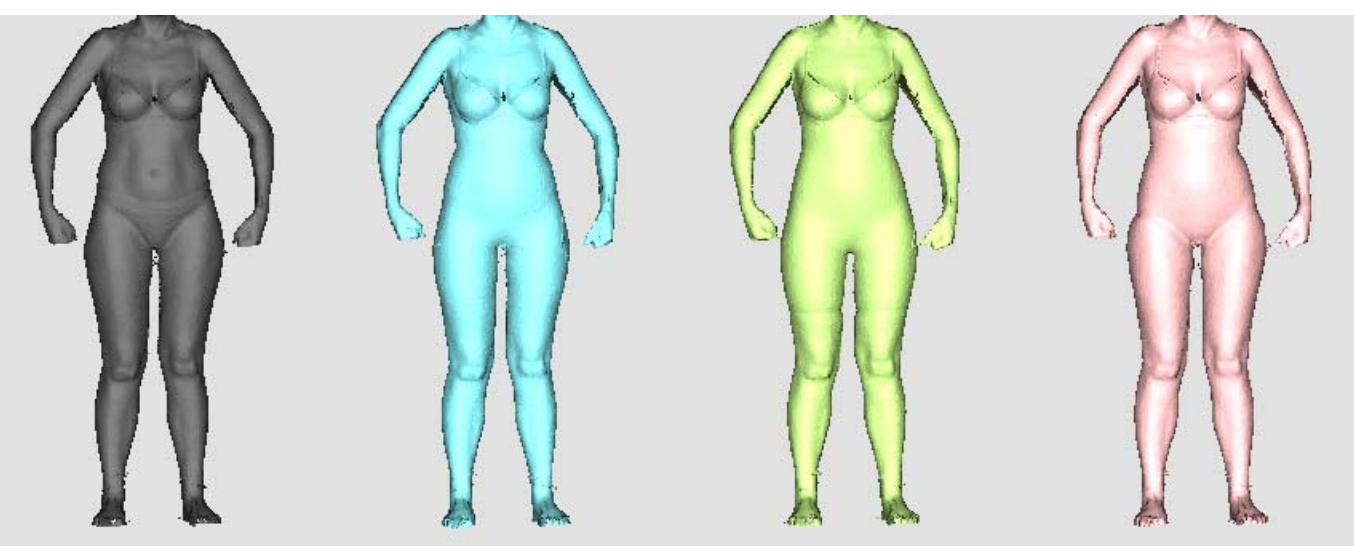

Fig. 4.3. Overview scans candidate $F_{1}$ without and with $S_{1}$ panty long, $S_{2}$ panty long and $S_{2}$ panty short.

In figure 4.4 the smoothing effect is given in detail for the z-axis over the y-axis in length for candidate F1 with different shaping garments (panty long S1, S2, S4, S5, S6) compared to the reference. It is detectable that the compression profile discussed in chapter 4.2 is not regularly distributed but the main objective "smoothing" well realized more or less.

Therefore the reduction of circumference measurements could be detected as an aid for the smoothing effect and is therefore not necessarily distributed constantly. 


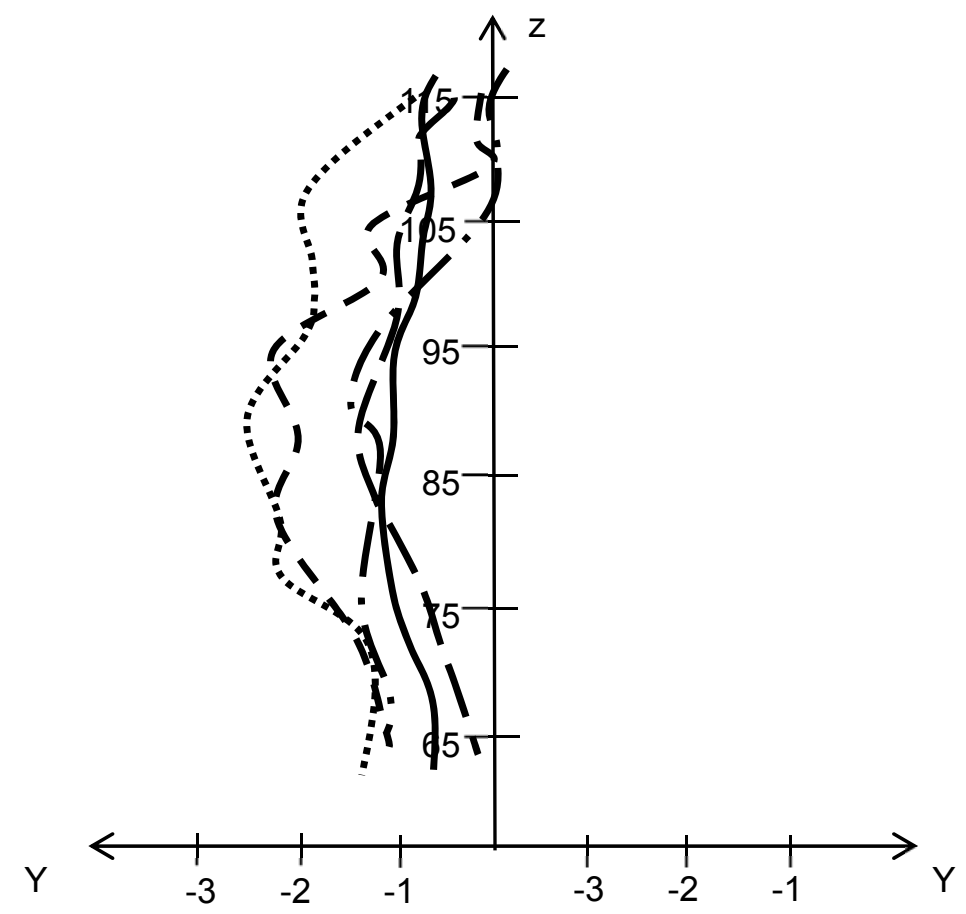

Fig. 4.4. Shaping profile, coordinate $z$ from ground $F_{1}$; difference [cm] shaping to reference.

$$
S_{1} ;---S_{2} ;-\cdots .-S_{4} ;-\ldots . S_{5} ;-.-S_{6}
$$

The so called smoothing effect can also be detected by photo illustration comparing fit, pleats and attachment of outer garments. In figure 4.5 female $F_{6}$ is shown wearing a simple t-shirt with and without shaping panty long $S_{2}$. It is visible that the smoothing effect produced by wearing shape wear takes place and the view on the front of the body shows- not major- but slight changes.
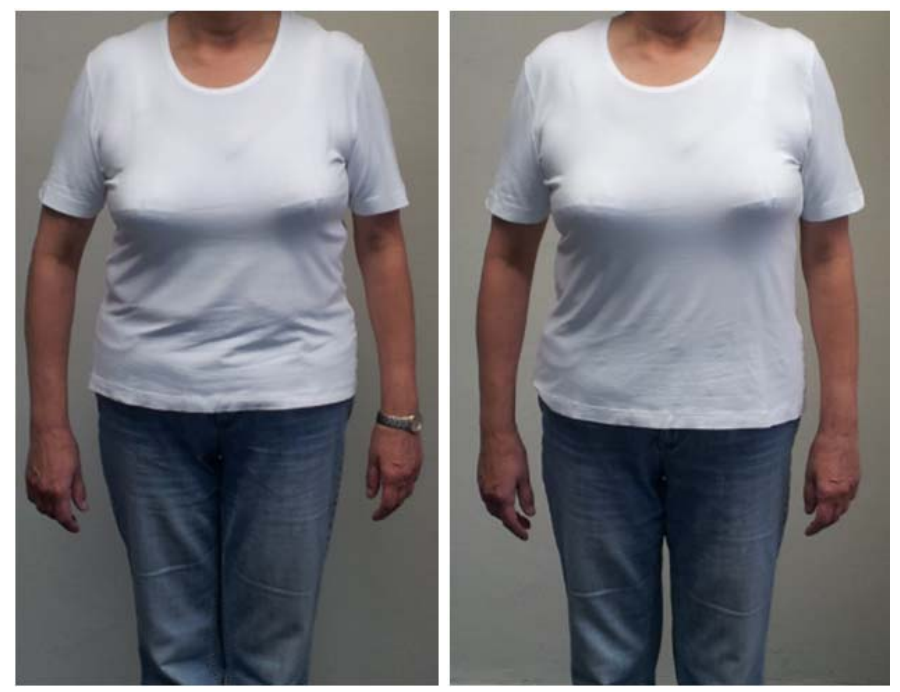

Fig. 4.5: Smoothing effect $F_{6}$ with $S_{2}$ panty long

\subsection{Virtual Fitting}

Scanning with and without shape wear generates different body measurements of the scanatars. Different garments- especially tight fitting shirts and dresses- have been selected for a virtual fitting test using different 3D CAD systems and could be tested successfully with regard to body distance control and pressure/tension mapping. 
In figure 4.6 a result of body distance control measurement is shown by comparing the fit of a simple dress for $F_{4}$ with and without wearing the product panty long of supplier $S_{6}$. Wearing body shaping garments causes an increase in body distance measurements for body parts mainly flexible to the compression applied and could be calculated by comparing the scanatar measurements.

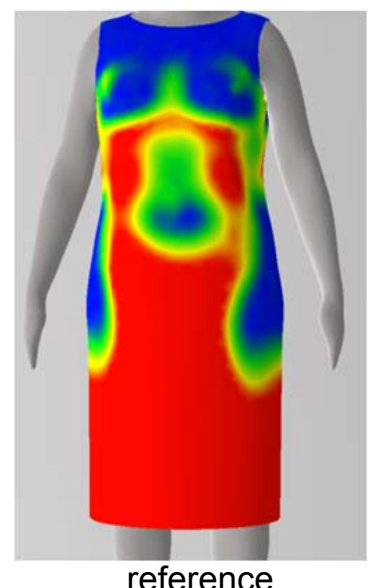

reference

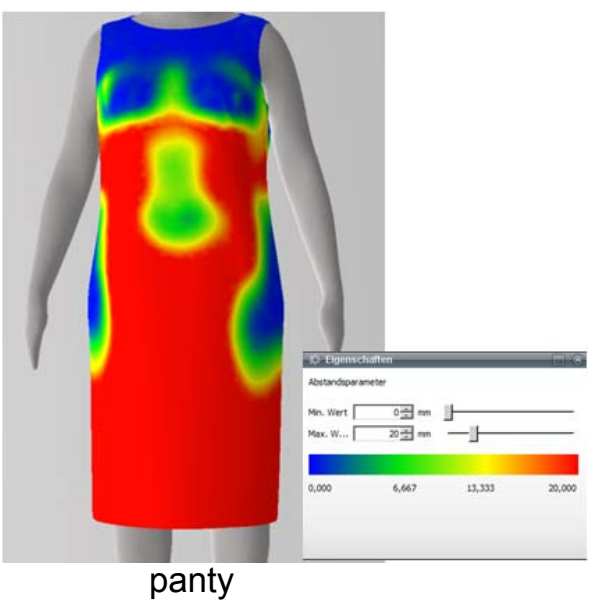

Fig. 4.6. Body distance control using vidya; scanatar $F_{4}$ with and without compression panty long $S_{6}$.

\section{Discussion and Conclusion}

Investigations have been carried out on shaping underwear structures within a sampling group of six females and different shape wear of six suppliers. By using body scanning technology it was possible to detect in a first step in detail the compression effects and profiles within this sampling group and to realize that not only the different body shapes but also the different age have a remarkable influence on the results obtained by wearing these structures. Wrong selection of size leads on one side to an enhanced shaping effect but on the other side to a greater increase in discomfort. Also selecting the "right" size and achieving a visible shaping effect was nevertheless always associated with discomfort over time. Environment and weather parameters such as hot summer days with high humidity, atmosphere and personal day performance/subjective well-being intensify the feeling of discomfort. Ongoing research is now focused on developing shaping structures with better compliance by changing material characteristics and improving details (waistband position and width, leg ends, seam constructions..), investigation on second layer shaping structures and the implementation within a complete clothing system.

\section{References}

1. Ernst, M., (2012): “3D CAD-Reality versus Virtuality”, Proceedings Assyst Fashion Forum, Munich, Germany

2. Ernst, M.; Güntzel, D.: 3D Simulation Tools for the clothing industry, Grafis Fashion Forum, Viersen, Germany, June 2, 2012

3. Ernst, M.; Rissiek, A.: Comparability Between Simulation And Reality In Apparel: A Practical Project Approach-From 3D-Body Scan To Individual Avatars And From 3D-Simulation In Vidya To Fitted Garments, Proc. of $2^{\text {nd }}$ International Conference on 3D Body Scanning Technologies, Lugano, Switzerland, 25-26 October 2011

4. Ernst, M.: Sizing and Fit- 3D Body Scanning, Cape Peninsula University of Technology, Cape Town, South Africa, March 14, 2011

5. Sorgenfrei J.: Body Shaping structures, master thesis, textile and clothing management, University of Albstadt-Sigmaringen, 2011

6. Ernst, M., (2010): "3D CAD Simulation Tools for Clothing Industry", Proceedings Assyst Fashion Forum, Munich, Germany

7. Ernst, M, (2009): "Powerful- 3D CAD in Application": Textile Network 4/09, pp. 20-21.

8. Ernst, M., (2008): "3D CAD- ways to Rapid Prototyping", fashion technics today, 05/08, pp. 12-13.

9. Lim, H. S.: Three Dimensional Virtual Try-on Technologies in the Achievement and Testing of Fit for Mass Customization. Dissertation to Graduate Faculty of North Carolina State University, Textile Technology and Management, Raleigh, 2009 